\title{
A study of intrauterine fetal death in a tertiary care hospital
}

\author{
Divya B.*, Ashwini Nayak U., Asha Swarup O.V.
}

Department of Obstetrics and Gynaecology, M. S. Ramaiah medical college and Teaching Hospital, Bangalore, India

Received: 10 November 2015

Revised: 23 November 2015

Accepted: 25 November 2015

\section{*Correspondence:}

Dr. Divya B.,

E-mail: divya_balu89@yahoo.com

Copyright: (C) the author(s), publisher and licensee Medip Academy. This is an open-access article distributed under the terms of the Creative Commons Attribution Non-Commercial License, which permits unrestricted non-commercial use, distribution, and reproduction in any medium, provided the original work is properly cited.

\begin{abstract}
Background: Intra uterine fetal death (IUFD) is the most traumatic event for the parents and the treating obstetrician. If the causes of IUFD can be found, an effective strategy for prevention can be formulated. This study was done to study the etiological factors and other determinants of IUFD.

Methods: A retrospective observational study was carried out in M. S. Ramaiah medical college and teaching hospital, Bangalore, India between December 2011 to December 2014. 120 cases of IUFD were included in this study.

Results: Out of 4103 deliveries that occurred during the study period, there were 120 IUFD (2.9\%). 52 cases (43.3\%) were referral cases. Majority were multigravida(n=73,60.8\%) aged less than 30 years $(n=96,80 \%)$ with 28 to 36 weeks period of gestation( $\mathrm{n}=66,55 \%) .91$ patients had presented with absent fetal movements(75.8\%).In $25 \%$ of the $\operatorname{cases}(n=30)$ there was preeclampsia and in $21.6 \%(n=26)$ of the cases there were no causes determined.99.1\% $(n=119)$ delivered by vaginal route.

Conclusions: The leading cause of IUFD in our study was preeclampsia. Majority of the cases were referred and they did not have regular antenatal checkups. A bigger impact in reduction of IUFD can be achieved if the importance of antenatal care can be stressed upon at the community level.
\end{abstract}

Keywords: Intra uterine fetal death, Risk factors, Stillbirth, Maternal factors

\section{INTRODUCTION}

Intrauterine fetal death is a tragic experience for not only the couple but also to the treating clinicians. The perinatal mortality surveillance report $(\mathrm{CEMACH})$ defined stillbirth as a baby delivered with no signs of life known to have died after 24 completed weeks of pregnancy World Health Organization-a stillbirth refers to a dead born fetus which can either occur before the onset of labour (ante-partum death) or during labour (intra-partum death) and is expressed per 1000 of total births Stillbirth is defined as in utero fetal death at 20 weeks of gestation or greater. ${ }^{1-3}$ The stillbirth rate varies sharply by country, from the lowest rates of 2 per 1000 births in Finland and Singapore and to highs of 47 in Pakistan and 42 in Nigeria and rates also vary widely within countries like in India, for example, rates range from 20 to 66 per 1000 births in different states. ${ }^{4}$ This study helps us to understand the risk factors associated with intrauterine fetal death and thereby help in preventing the recurrences.

\section{METHODS}

This is a retrospective study conducted in M. S. Ramaiah medical college and teaching hospital from December 2011 to December 2014. Intrauterine fetal deaths above 22 weeks period of gestation and or above 500 grams of weight were included. Detailed history of the patient was collected from the hospital records- such as Age, parity index, referred or a booked case, associated risk factors such as preeclampsia, GDM, Rh negative pregnancy, and oligohydramnios. Data regarding the mode of delivery and the baby details such as birth weight, macerated or 
fresh still born, placental pathology and presence of retro placental clots were recorded.

\section{Statistical analysis}

All the data analysis was carried out employing SPSS 18.0 version. All the quantitative variables were expressed as mean and standard deviation. Qualitative variables were expressed as percentages.

\section{RESULTS}

Table 1: Maternal characteristics.

\begin{tabular}{|c|c|c|c|c|}
\hline Age & No. of cases & \multicolumn{2}{|l|}{$\%$} & \multirow{3}{*}{$\begin{array}{l}25.72 \\
\text { (SD-4.4964 }\end{array}$} \\
\hline$<30$ years & 96 & \multicolumn{2}{|l|}{80} & \\
\hline$>30$ years & 24 & \multicolumn{2}{|l|}{20} & \\
\hline \multicolumn{4}{|l|}{ Parity } & \multirow{3}{*}{$\begin{array}{l}2.05 \\
(S D-1.0359)\end{array}$} \\
\hline primi & 47 & 39. & & \\
\hline multi & 73 & 60. & & \\
\hline \multicolumn{4}{|c|}{ Period of gestation } & \multirow{4}{*}{$\begin{array}{l}29.71 \text { weeks } \\
\text { (SD-5.3376) }\end{array}$} \\
\hline$<28 w k s$ & 40 & 33. & & \\
\hline $28-36$ & 66 & 55 & & \\
\hline $37-42$ & 14 & 11. & & \\
\hline \multicolumn{4}{|l|}{ Complaints } & \\
\hline \multicolumn{2}{|c|}{ Absent fetal movements } & & 75.8 & \\
\hline \multicolumn{2}{|c|}{ Decrease fetal movements } & 12 & 10 & \\
\hline \multicolumn{2}{|c|}{ Pain abdomen } & 5 & 4.2 & \\
\hline \multicolumn{2}{|c|}{ Leak pv } & 2 & 1.7 & \\
\hline
\end{tabular}

During the period of this study, there were 4103 deliveries. Out of which 120 cases were intrauterine fetal death $(2.9 \%)$. Incidence of intrauterine fetal death in our hospital was 29.2 per 1000 live births Out of which 52 cases $(43.3 \%)$ were referral cases. Majority of the cases $(n=73)$ were multigravida $(60.8 \%)$ and $39.1 \%$ were primigravida $(\mathrm{n}=47)$. The mean parity was 2.05 (std deviation-1.0359) Majority of patients were aged less than 30 years $(n=96,80 \%)$ with the mean age of 25.72 (std deviation-4.4964) with 28 to 36 weeks period of gestation $(n=66,55 \%)$. The mean gestational age was 29.71 weeks with standard deviation of 5.3376. 40 patients $(33.3 \%)$ had IUFD at $<28$ weeks of gestation. $11.7 \%(\mathrm{n}=14)$ of the patients had term IUFD. 91 patients had presented with absent fetal movements $(75.8 \%)$ while $10 \%(\mathrm{n}=12)$ came with decreased fetal movements. $4.2 \%$ $(n=5)$ of patients were admitted with pain and $1.7 \%(n=2)$ with leak per vagina (Table 1 ). Out of 120 patients with IUFD, 25\% ( $n=30)$ had preeclampsia, 9.2\% ( $n=11)$ had hypothyroidism, $7.5 \% \quad(\mathrm{n}=9)$ of oligohydramnios and IUGR, 6.6\% $(n=8)$ with anaemia, 5.8\% $(n=7)$ had GDM, $4.2 \%(n=5)$ with previous history of IUFD, $3.3 \%(n=4)$ with $\mathrm{Rh}-\mathrm{ve}$ status, $2.5 \% \quad(\mathrm{n}=3)$ each of gestational hypertension, chronic hypertension and abruption, $1.7 \%$ $(n=2)$ with antepartum eclampsia and $0.8 \%(n=1)$ with previous history of abruption. In $21.7 \%(n=26)$ there were no causes found (Table 2). The severe complication noticed in the mother were $-15 \% \quad(n=18)$ of patients needed blood transfusion due to DIC, $4.2 \%(n=5)$ had a prolonged stay in the hospital for more than 7 days, $3.3 \%$ $(\mathrm{n}=4)$ needed ICU care and $0.8 \%(\mathrm{n}=1)$ had postpartum psychosis (Table 3$) .99 .1 \%(n=119)$ had vaginal delivery out of which $28.3 \%(n=34)$ had spontaneous onset and $70.8 \%(n=85)$ were induced. Only 1 patient had LSCS. Fetal characteristics revealed $51.6 \%(n=62)$ were males while $48.6 \%(n=58)$ were females. $68.3 \%$ were fresh still births $(n=82)$ and only $31.7 \%(n=38)$ were macerated. 1 fetus was born with a true knot of the umbilical cord, 5 $(4.2 \%)$ had tight cord around neck (Table 4$)$.

Table 2: Causes.

\begin{tabular}{|lll|}
\hline $\begin{array}{l}\text { Maternal } \\
\text { characteristics }\end{array}$ & No of cases & Percentage \\
\hline Preeclampsia & 30 & $25 \%$ \\
\hline Abruption & 3 & $2.5 \%$ \\
\hline Previous h/o abruption & 1 & $0.8 \%$ \\
\hline Antepartum eclampsia & 2 & $1.7 \%$ \\
\hline Gestational HTN & 3 & $2.5 \%$ \\
\hline Chronic HTN & 3 & $2.5 \%$ \\
\hline IUGR & 9 & $7.5 \%$ \\
\hline Oligohydramnios & 9 & $7.5 \%$ \\
\hline GDM & 7 & $5.8 \%$ \\
\hline Anemia & 8 & $6.6 \%$ \\
\hline Thrombocytopenia & 6 & $5 \%$ \\
\hline Hypothyroidism & 11 & $9.2 \%$ \\
\hline Rh - ve status & 4 & $3.3 \%$ \\
\hline Previous h/o IUFD & 5 & $4.2 \%$ \\
\hline Unexplained & 26 & $21.6 \%$ \\
\hline
\end{tabular}

Table 3: Complications.

\begin{tabular}{|lll|}
\hline $\begin{array}{l}\text { Maternal } \\
\text { complications }\end{array}$ & No of cases & Percentage \\
\hline Blood transfusions & 18 & $15 \%$ \\
\hline ICU care & 4 & $3.3 \%$ \\
\hline Sepsis & 3 & $2.5 \%$ \\
\hline Hospital stay > 7 days & 5 & $4.2 \%$ \\
\hline Postpartum psychosis & 1 & $0.8 \%$ \\
\hline
\end{tabular}

Table 4: Fetal characteristics.

\begin{tabular}{|lll|}
\hline Fetal characteristics & No of cases & $\%$ \\
\hline Sex-male & 62 & $51.6 \%$ \\
\hline Sex-female & 58 & $48.3 \%$ \\
\hline Gross features macerated & 38 & $31.7 \%$ \\
\hline Fresh stillbirths & 82 & $68.3 \%$ \\
\hline Tight cord around neck & 5 & $4.2 \%$ \\
\hline True knot of cord & 1 & $0.8 \%$ \\
\hline
\end{tabular}

\section{DISCUSSION}

In the present study, incidence of IUFD was 29.2 per 1000. In study by Maleckiene L and Singh $\mathrm{N}$ et al the IUFD rate was 40 per 1000 . The stillbirth rate varies across the country with Karnataka having a stillbirth rate 
of $14 .^{5-7}$ In a study by Patel $\mathrm{S}$ et al, incidence of IUFD was higher among 56 (70\%) emergency admissions compared to $24(30 \%)$ registered admissions. ${ }^{8}$ In the present study, out of 120 IUFD cases, 52 cases $(43.3 \%)$ were referral cases. Majority of the cases with IUFD were multigravida $(60.8 \%)$. This is similar to the study by Korde-NV et al. in which $51.6 \%$ of the multigravida had stillbirths. ${ }^{9} 80 \%$ of patients were aged less than 30 years in our study which is similar to the study by $\mathrm{C}$ Okeudo et al in which the age group of 26-30 had the highest stillbirth prevalence of $79(38.3 \%, 79 / 206) .{ }^{10} 55 \%$ of the IUFD occurred between 28 to 36 weeks period of gestation. This is comparable to the study by Patel $\mathrm{S}$ et al, $50(62.5 \%)$ were between $25-32$ weeks of gestational age. ${ }^{8}$ In our study $75.8 \%$ of the patients had presented with absent fetal movements while $10 \%$ had come with decreased fetal movements. In study by Tamrakar SR et al, in more than half of the recorded cases $(54.7 \%)$ the complaint was of reduced or absent foetal movements. ${ }^{11}$ In our study history of previous IUD was seen in previous history of IUFD in 3.3\% similar to study by Singh N et al in which it was $4.05 \%$ cases. $^{6}$ In the present study, $25 \%$ had preeclampsia and $2.5 \%$ had abruption. Most of the other studies such as study by Patel S,PIH and eclampsia together accounted for $27(33.7 \%)$ cases of IUFD and abruptio placenta due to PIH accounted for $10(12.5 \%){ }^{8}$ In the present study GDM contributed to $4.2 \%$ of the IUFD which is similar to study by Anjali C. ${ }^{12}$ In present study, $21.7 \%$ were unexplained IUFD as compared to $38.7 \%$ in Patel $\mathrm{S}$ et al study and Singh $\mathrm{N}$ et al it was $33 \%$. $^{6,8} 1$ fetus was born with a true knot of the umbilical cord and $4.2 \%$ had tight cord around neck in this study which concurs with study by Singh $\mathrm{N}$ in which cord complications like cord prolapse and true knot was seen in $4.72 \%$ of patients. ${ }^{6}$ In this study, $51.6 \%$ of the dead fetus were males and $48.6 \%$ were females. In a study by Safarzadeh A, among 807 totals IUFD, there were 410 $(50.8 \%)$ male dead fetus and $397(49.1 \%)$ female dead fetus. ${ }^{13} 68.3 \%$ were fresh still births and only $31.7 \%$ were macerated which is similar to study by Katherine J. Gold et al in which $33(70 \%)$ fetuses were fresh and $14(30 \%)$ were macerated. ${ }^{14} 99.1 \%$ had vaginal delivery in our study while the mode of delivery was vaginal in $87.4 \%$ in study by Ifnan F et al. ${ }^{15}$ Duration of hospital stay $>7$ days was seen in $9.45 \%$ patients in Singh $\mathrm{N}$ et al study while in our study $4.2 \%$ had a prolonged hospital stay. ${ }^{6}$ In this study $15 \%$ received blood transfusion due to DIC compared to Patel S study in which DIC occurred in $22.5 \%$ and all of them required transfusion of blood components. $^{8}$

\section{CONCLUSION}

IUFD rate still remains high. As seen in this study majority of the cases have been referred and most of the women have not had antenatal care regularly. Better antenatal care and evaluation of the cases can help in reducing this tragic event.
Funding: No funding sources

Conflict of interest: None declared

Ethical approval: Not required

\section{REFERENCES}

1. Confidential Enquiry into Maternal and Child Health (CEMACH). Perinatal Mortality 2007:United Kingdom. CEMACH: London, 2009.

2. World Health Organization (WHO). Neonatal and perinatal mortality, country, regional and global estimated. Department of Making Pregnancy safer. Geneva: WHO, 2004.

3. Silver RM, Varner MW, Reddy U. Work-up of stillbirth: a review of the evidence Am J Obstet Gynecol. 2007;196(5):433-44.

4. Lawn JE, Gravett MG, Nunes TM, Rubens CE, Stanton C. The GAPPS Review Group. Global report on preterm birth and stillbirth (1 of 7): definitions, description of the burden and opportunities to improve data. BMC Pregnancy Child-birth. 2010;(Suppl 1):S1,1471-2393.

5. Maleckiene L, Nadisauskiene R, Stankeviciene J, Cizauskas A, Bergstrom S. A case reference study on fetal bacteremia and late fetal death of unknown etiology in Lithuania. Acta Obstet Gynecol Scand. 2000;79:1069-74.

6. Singh N, Pandey K, Gupta N, Arya AK, Pratap C, Naik R. A retrospective study of 296 cases of intra uterine fetal deaths at a tertiary care centre. Int $\mathbf{J}$ Reprod Contracept Obstet Gynecol. 2013;2:141-6.

7. Bhati DK. Stillbirths: A high magnitude public health issue in India .South East Asia Journal of Public Health. 2013;3(1):3-9.

8. Patel S, Thaker R, Shah P, Majumder S. Study of causes and complications of intra uterine fetal death (IUFD). Int J Reprod Contracept Obstet Gynecol. 2014;3:931-5.

9. Korde NV, Gaikwad P. Causes of stillbirth. J Obstet Gynaecol India. 2008;58(4):314-7.

10. Okeudo C, Ezem BU, Ojiyi EE. Stillbirth Rate in a Teaching Hospital in South-Eastern Nigeria: A Silent Tragedy Ann Med Health Sci Res. 2012;2(2):176-9.

11. Tamrakar SR, Chawla CD.Intrauterine Foetal Death and Its Probable Causes: Two Years' Experience in Dhulikhel Hospital - Kathmandu University Hospital Kathmandu University Hospital. Kathmandu Univ med J. 2012;10(4):44-8.

12. Choudhary A, Gupta V. Epidemiology of Intrauterine Fetal Deaths: A Study in Tertiary Referral Centre In Uttarakhand. Journal of Dental and Medical Sciences. 2014;13(3):3-6.

13. Safarzadeh A, Ghaedniajahromi $M$, Ghaedniajahromi M. Intra Uterine Fetal Death and Some Related Factors: A Silent Tragedy in Southeastern Iran J Pain Relief 2014;3:1.

14. Gold KJ, Abdul-Mumin AS. Assessment of "fresh" versus "macerated" as accurate markers of time since intrauterine fetal demise in low-income countries.Int J Gynaecol Obstet. 2014;125(3):223-7. 
15. Ifnan F, Jameel MB. Maternal morbidity and mortality associated with delivery after intrauterine fetal death. J Coll Physicians Surg Pak. 2006;16(10):648-51.
Cite this article as: Balu D, Nayak A, Swarup A. A study of intrauterine fetal death in a tertiary care hospital. Int J Reprod Contracept Obstet Gynecol 2015;4:2028-31. 